\title{
ANTECEDENTES HISTÓRICOS DEL DERECHO AMBIENTAL COLOMBIANO
}

\author{
Eduardo Arturo Kerguelén Durango \\ ekerguelen_d@hotmail.com
}

\begin{abstract}
Resumen
El presente escrito es una revisión bibliográfica ubicada en el campo de la normatividad del derecho público, más concretamente el derecho ambiental. Se revisó los antecedentes del derecho ambiental, considerando los referentes en el derecho romano en el manejo de estos recursos. A pesar que el desarrollo del derecho ambiental actual está regido por el aspecto público y administrativo del mismo, sería el Derecho privado el que dio las primeras soluciones a los problemas relacionados con aspectos ambientales, estando siempre el derecho civil presente en materia medioambiental sobre todo en el Derecho romano. En el derecho romano, algunas de las normas, consideradas hoy día protectoras del medio ambiente, estaban ubicadas en otros sectores del ordenamiento jurídico, tales como organización del territorio, urbanismo, sanidad, propiedad, servidumbre, relaciones de vecindad o bien obedecían a diferentes motivaciones o intereses económicos. El análisis muestra que los antecedentes del derecho ambiental, en sus inicios, estaba encaminado más a la protección de la propiedad privada que a la naturaleza propiamente, con notoria deficiencia legislativa en el sector medioambiente. Lo anterior prescribe que en nuestro país la legislación ambiental y, más propiamente, lo atinente a recursos naturales, en sus inicios fueron manejados por el Código Civil como herencia de la concepción romanística y el legado del Código Napoleónico. Finalmente, podemos mencionar que en el país, la incipiente cultura legal ambiental se sugiere estar relacionada con la marginalidad académica existente y la relativa novedad en materia de derecho ambiental, que surge a partir del año 1973 con la notoria influencia de la Conferencia de Estocolmo de 1972, dando nacimiento a la promulgación de la Ley 23 de 1973.
\end{abstract}

A lo largo de la historia, las primeras normas conocidas en materia ambiental fueron establecidas con el objetivo de proteger la propiedad privada más que al aspecto ambiental propiamente dicho. Esta característica sugiere, inicialmente, ubicar al derecho ambiental dentro de las disciplinas que hacen parte del derecho privado, principalmente, en el derecho civil. Al respecto, Llodrá (2008), considera que, a pesar que el desarrollo del Derecho ambiental actual está regido por el aspecto público y administrativo del mismo, sería el Derecho privado el que dio las primeras soluciones a los problemas relacionados con aspectos ambientales, estando siempre el Derecho civil presente en materia medioambiental sobre todo en el Derecho romano.

A pesar que en nuestro país y el resto del continente la protección del medio ambiente es relativamente reciente, se conocen normas históricas con tal finalidad; sin embargo, Jordano (1995), considera preciso aclarar que históricamente no se podría hablar de un 
Derecho ambiental tal y como lo conocemos hoy día, sino que algunas de esas normas, consideradas hoy día protectoras del medio ambiente, se ubicaban en otros sectores del ordenamiento jurídico - v. gr. organización del territorio, urbanismo, sanidad, propiedad, servidumbre, relaciones de vecindad- o bien obedecían a diferentes motivaciones 0 intereses económicos.

Zambrana (2011), considera que los precursores en la defensa del medio ambiente fueron los babilonios con algunas disposiciones en el Código de Hammurabi, en el cual se puede encontrar el antecedente histórico más antiguo relacionado con la defensa jurídica del medio ambiente, relacionado con la protección de los animales. En este documento se prohibía la sobreexplotación o la utilización indebida o indolente de los mismos. v. gr. quien alquilaba un buey y, por negligencia, le causaba la muerte o le rompía un casco o le cortaba el tendón del cuello -haciéndolo inservible para el trabajo- debía pagar una especie de multa al propietario, con otro buey equivalente (Lara, 1982). Si quien arrendaba un buey, le destruía un ojo tenía que abonar a su propietario la mitad de su precio, si le rompía un cuerno, le cortaba la cola o le dañaba la espalda debía cancelar la cuarta parte (Lara, 1982).

Por otro lado, quien robaba cereales y con ello perjudicaba a los animales debilitándolos, tenía que devolver el doble del grano robado. La Ley del Talión más estricta era aplicada a quien dejaba morir al buey o al cordero que le había sido confiado (buey por buey y cordero por cordero). Por su parte, el pastor al que se le confiaba ganado para apacentarlo y dejaba disminuir el ganado, habiendo cobrado ya por dicho trabajo, debía entregar las crías y los beneficios. Asimismo, el pastor que, por negligencia, permitía que se propagase la sarna 0 cualquier infección en el rebaño tenía que restituir el ganado perdido (Lara, 1982).

Como podemos observar, todas las disposiciones relacionadas en el texto anterior, estaban dirigidas a la protección de la propiedad privada o a los animales como instrumentos de trabajo para la agricultura, más que a las especies en sí mismas como elementos del medio ambiente (Jaquenod, 1989).

Adicionalmente, se observan normas relativas a los daños ocasionados por el agua en las tierras de labranza, las cuales están más próximas al Derecho penal (Zambrana, 2011). La negligencia a la hora de reforzar un dique que provocaba una fuga de agua que devastaba las tierras del vecino obligaba al responsable a compensar el grano perdido. En caso de insolvencia por parte del culpable, la pena subsidiaria consistía en venderlo junto con sus bienes y el importe de la venta se repartía entre los ocupantes de las tierras dañadas. De la misma forma, el que abría una alberca para la irrigación de forma negligente permitiendo 
que las aguas destruyesen el fundo vecino debía reparar el daño ocasionado a la cosecha (Lara, 1982).

En el "Código de Hammurabi" donde no existió una pena asignada a quien provocara un incendio, sí se castigaba con el lanzamiento al fuego a aquél que se apropiara de algún bien mueble que con ocasión de un incendio fortuito en casa de un tercero, fuera a la misma con la intención inicial de apagarlo; es decir, se refiere a un delito cometido aprovechando el incendio considerado como circunstancia favorecedora del delito (Garcia, 1998). Esta norma tuvo su continuidad en el ordenamiento jurídico romano: "el edicto pretorio concedía una acción venal contra la persona que aprovechándose de un incendio sustrajera bienes o adquiriese los bienes sustraídos".

\section{Derecho romano}

Desde el punto de vista del derecho romano, los recursos naturales -la tierra, el agua, los yacimientos minerales, la flora, la fauna, los recursos panorámicos y el ambiente en sífueron, en términos generales, "res communi", es decir, cosas de la comunidad, que podían ser empleadas por todos, salvo en cuanto hubieren determinado derechos particulares sobre pequeñas porciones individuales (FUP, 2008). Mientras los usos particulares de los recursos no afectaron en general la naturaleza, ningún obstáculo legal o económico impidió el uso y el abuso de tales bienes (FUP, 2008).

Oroz \& Marcos (1994), sostuvieron que de acuerdo con San Isidoro, inicialmente, los romanos enterraban a sus muertos en sus propias casas, pero con el paso del tiempo esta costumbre fue prohibida por las normas. Dentro de las primeras medidas del Derecho romano de carácter ambiental se puede visualizar que en la Ley de las XII Tablas, se tenía prohibido enterrar a los muertos dentro de la ciudad (Rascón \& García, 1993). Estos autores aseguran que Cicerón prohibía tanto la incineración de personas como situar una tumba en un radio de 60 pies de una casa ajena, contra la voluntad de su dueño. Sin duda alguna estas normas se constituyeron en una medida higiénica de salud pública muy importante en materia ambiental, que hizo que éstos se enterraran en las necrópolis, situadas a los lados de las carreteras y los caminos y en las zonas habilitadas para ello a las afueras de las ciudades (Romanorum Vita, 2013).

Una de las primeras disposiciones dirigidas de forma directa a preservar el medio ambiente con base en un interés general más que individual se observa en el Digesto y tiene como objeto la protección de las aguas (Zambrana, 2011). Se trata de un texto de las sentencias de Paulo que se sitúa en el título de extraordinariis criminibus en el que se recoge la palabra 
contaminaverit. Al respecto, Zamora (2003), asegura que la contaminación no aparece en este fragmento como una forma autónoma de ilícito penal; mientras que Jordano (1993) plantea que se trata de un delito que se podría considerar precedente del delito ecológico y estaría sometido a un castigo severo.

De otro lado, Fedeli (1990), sostiene que en ausencia de fenómenos de contaminación de las aguas en el derecho romano, comparables a los modernos, los ejemplos que aparecen en esta legislación sobre la materia, manifiestan una constante preocupación por preservar su pureza. Este mismo autor, exterioriza los consejos de Vitruvio para evitar la impureza del agua y garantizar su calidad y alude a las ideas de éste acerca de la relación entre la salubridad del agua y la constitución física y el aspecto saludable de los que la beben, haciéndose eco de un claro determinismo ambiental.

Adicionalmente, en un fragmento del Digesto se contempla la contaminación de las aguas del fundo vecino por instalación de sistemas hidráulicos para uso industrial de lavanderías - lavaderos de tintorería (fullonicae) junto a una fuente, perjudicando a los otros propietarios, aguas abajo, con agua contaminada (Zambrana, 2011). También estaba contemplada la obligación de los propietarios de los terrenos por donde pasaban los acueductos limpiarlos. El incumplimiento era sancionado con la pérdida de los bienes, puesto que el fisco se quedaba con el predio de aquél cuya negligencia había contribuido a la ruina del acueducto (Zambrana, 2011). Una constitución de Zenón prohibió que se plantasen árboles junto a los acueductos para evitar que sus raíces afectasen a las paredes del mismo y quien lo hiciera sufriría el embargo de sus bienes (Zamora, 2003).

Se concedía importancia en el ordenamiento jurídico romano a la limpieza y reparación de canales y cloacas, cuyo fin era evitar pestilencias que pusieran en riesgo la salubridad y la seguridad de las ciudades, ya que las inmundicias de las cloacas provocaban malos olores y ruinas (Di Porto, 1990). El emperador Julio César expidió una norma ambiental que prohibía la circulación de carruajes en algunos barrios de Roma y Pompeya, en razón al ruido que emitían y a la producción de excrementos que contaminaban dichas ciudades.

El Fuero Juzgo, que fue la recopilación legislativa del siglo VII que regulaba la nueva organización que los visigodos intentaron implantar en la Hispania posromana, prestaba una atención especial a los asuntos del agua, castigando duramente los robos en los molinos (Mohedano, 2004). En esta recopilación y la ley de las siete partidas, se consideró a los ríos y caminos como bienes comunes en la época de la colonia. 
Durante el periodo de la Edad Media, la cual transcurrió desde la desintegración del Imperio Romano de Occidente en el 476 d.c., hasta la caída de Constantinopla en 1453, se caracterizó por la manera sesgada de mirar el mundo. Este periodo comprendió la época de las cruzadas -entre el siglo XI y XIII-, lo cual coincide con la fecha de la invención de la imprenta en 1455 y el descubrimiento de América en 1492. Durante esta etapa, se avanzó con el desarrollo de la agricultura lo cual generó la tala de bosques, no sólo para obtener tierras de cultivo, sino también como combustible y para la construcción de ciudades. Adicionalmente, la creciente demanda de madera para la construcción de barcos y fabricación de carbón vegetal extendió la deforestación en Europa. Sin embargo, en Europa en el siglo XVII se empezaron políticas de reforestación y conservación de los bosques, aunque muy limitadas y sin repercusión práctica real, v. gr. las zonas de caza de reyes y nobles y lugares de recreo han sido especialmente protegidos a lo largo de los siglos y se han conservado de forma excepcional (Echarri, 2007).

En la recopilación de las leyes de Indias y en la novísima recopilación que contienen las leyes de 1792 y 1796 sobre la protección de ríos y cañadas, caminos y terrenos destinados a la ganadería, también se contemplan medidas de protección a los montes públicos y privados.

Simón Bolívar en su calidad de Presidente de la Gran Colombia expidió el decreto 5 de julio de 1825 para proteger la fauna en Chuquisaca, también el decreto de 19 de diciembre del mismo año, que buscaba proteger el agua en Bogotá. El decreto de diciembre 02 de 1827 sobre la policía general, donde se reglamentaba el manejo de la salubridad del ambiente y la estética de las poblaciones y, más tarde, el decreto de julio 31 de 1829 que buscaba conservar los bosques de los que se venía extrayendo la madera y las sustancias medicinales.

El siglo XIX marcó un cambio radical en la explotación de los recursos naturales con la invención de la máquina de vapor, generándose de esta manera la primera emanación de gases al ambiente; adicionalmente, se empezó a utilizar energía eléctrica y comenzaron a funcionar las primeras industrias químicas (Mohedano, 2004). Hubo una expansión y multiplicación de la explotación de carbón y a mediados de siglo se comenzó el uso del petróleo, lo cual generó la creación de varias sociedades protectoras denominadas "sociedades conservacionistas". Durante este periodo, se creó el parque nacional de Yosemite en Estados Unidos, siendo el primero del mundo, y más tarde fue creado el de Yellowstone (Echarri, 2007).

A finales de siglo fueron aprobadas algunas normas tendientes a controlar las emanaciones de humos y emisiones de las fábricas químicas de jabones en Inglaterra y otros países industrializados, como también la prohibición de la creciente contaminación de fuentes y 
ríos. No obstante, a pesar de ser esbozos de normas protectoras que señalaban el comienzo de una sensibilidad sobre protección del medio ambiente, estaban lejos de una verdadera reglamentación ambiental, pues no especificaban las cantidades de contaminantes prohibidos.

\section{Edad Moderna}

En la década de los 30 y 40 fueron aprobadas algunas legislaciones sobre bosques, suelos, aguas y fauna -particularmente recursos pesqueros-, que denotan un impulso a la regulación. En la lenta construcción de esas primeras legislaciones y organizaciones que se registra en algunos países, durante la primera mitad del siglo, así como en las visiones que se van introduciendo sobre el manejo de los recursos naturales, se encuentran los antecedentes mediatos de la gestión ambiental moderna (Castro, 1994; Alvarenga \& Lago, 2000; De Alba, 2000; Espino, 2000; Espinoza, 2000).

En América Latina, desde finales del siglo XIX y principios del siglo XX surgieron nuevas reglamentaciones sobre la explotación y el uso de los recursos naturales renovables, por lo que es posible distinguir tres periodos (FUP, 2008):

1. El primero corresponde al periodo de producción legislativa iniciado en el siglo XIX con la promulgación de las primeras constituciones y códigos civiles, los cuales estuvieron caracterizados por disposiciones dispersas sobre el uso de los recursos naturales. Estas normas, muchas existentes aun, fueron ajenas a consideraciones ecológicas y al concepto de derecho ambiental. Este periodo alcanzó su máximo auge en la posguerra, a través del modelo de «desarrollo» propagado por las instrucciones Breton Woods.

2. El segundo periodo se inició con la Conferencia sobre el Medio Humano (Estocolmo 1972), dando inicio a proyectos tendientes a la recuperación y sistematización de elementos del derecho ambiental esparcidos en decretos y reglamentaciones sobre los recursos naturales renovables y no renovables, reunir piezas de legislación dispersas sobre los recursos naturales, la salud pública, las aguas, los bosques, la caza, la pesca, el control sanitario y el sistema de parques nacionales.

Durante este período se gestaron concepciones críticas sobre el modelo de desarrollo dominante en América Latina y se ensayaron metodologías 
para incorporar la "dimensión ambiental" en los planes y proyectos de desarrollo. Sin embargo, esta época se caracterizó por la ausencia de voluntad política y por la falta de una significativa inversión pública para hacer efectiva la protección ambiental. El nivel de «conciencia ambiental» fue especialmente bajo entre los ejecutores de decisiones públicas. La percepción de la crisis ambiental a escala mundial fue contemporánea del reporte «Nuestro Futuro Común» de la Comisión Mundial de Medio Ambiente y Desarrollo, con cuya publicación en 1987 se inicia el proceso global de interés ambiental a escala planetaria que concluye cinco años más tarde con la Cumbre de la Tierra en Río de Janeiro (1992).

3. El tercer periodo hace referencia al reconocimiento del derecho a un ambiente sano y su consagración como derecho fundamental y/o colectivo en las constituciones de la mayoría de los países de la región. El paso más significativo ha sido la consolidación en la década de los noventa de la tendencia a elevar los principios ambientales a rango constitucional. En las constituciones de los países latinoamericanos se encuentran, en primer lugar, preceptos que consagran el dominio público y la propiedad del Estado sobre el ambiente y los recursos naturales del país; en segundo lugar, principios de política ambiental y, finalmente, aquellos que reconocen el derecho al ambiente como derecho fundamental, colectivo o social, así como principios de equidad intergeneracional $y$ «derechos de la naturaleza». Otro avance significativo ha sido la consagración de instrumentos y remedios legales de justicia constitucional para garantizar los derechos humanos que han estimulado la democratización del acceso a la justicia como vías efectivas y eficientes para garantizar la protección de los derechos fundamentales. Respecto a las tarifas legales de responsabilidad daños ambientales, la tendencia es hacia el establecimiento de la responsabilidad objetiva y la presunción de responsabilidad asociada a actividades peligrosas o de riesgo ambiental. La ampliación de los mecanismos de control y la definición precisa de sanciones administrativas y medidas preventivas es un rasgo sobresaliente de la administración ambiental. La normativa penal ecológica se viene perfilando como un campo especializado del derecho penal y la política criminal en medio ambiente es un tema significativo en la agenda académica. 
Actualmente, el campo de los recursos genéticos constituye por si mismo uno de los mayores desafíos que deberá enfrentar el derecho ambiental en el inmediato futuro, especialmente respecto a la amenaza que representa la manipulación genética sin límites éticos y legales para la biodiversidad y la integridad del ambiente. En este sentido será necesario avanzar hacia una armonización regional del marco legal de la bioseguridad.

Adicionalmente, el transporte motorizado, "núcleo duro" de la gestión ambiental, entre cuyas externalidades deben contabilizarse tanto por los graves impactos sobre la calidad del aire en las ciudades y su contribución al incremento de los gases de efecto invernadero como sus costos sociales.

Después de la Segunda Guerra Mundial, comenzó a fraguarse la visión del aprovechamiento racional de los recursos naturales, cuyo fin es protegerlos y de esta manera asegurar su renovación y posterior explotación. Se empezó a introducir el concepto recurso renovable, siendo más un medio para asegurar el flujo continuo de los productos de la naturaleza, que para garantizar la conservación de los ecosistemas. Esta visión toma un impulso gradual en América Latina y el Caribe entre los años cincuenta y setenta (Hays, 1998).

En Colombia, antes de la expedición del Código de los Recursos Naturales y del Medio Ambiente en 1974, los recursos naturales fueron manejados con criterios patrimoniales y de explotación. Existieron algunas normas fragmentadas y dispersas, v.gr., el decreto 1279, Departamento de Tierras Baldías y Bosques Nacionales en el Ministerio de Obras Públicas, el cual permitía el pago de obras con bosques. De otro lado, el Código Fiscal Nacional contentivo de normas sobre uso de los bosques en terrenos baldíos con fines tributarios, situación corregida con la Ley 119, que creó la Comisión Forestal en 1989. El decreto 376 sobre pesca marítima, el decreto 1975 de 1959 sobre pesca en aguas dulces de uso público y se creó el INDERENA (Sánchez, 2002).

A la postre, y a partir de la Convención de Estocolmo 1972, el Congreso colombiano expidió la ley 23 de 1973 que concibió al medio ambiente como patrimonio común de los colombianos y autorizó al ejecutivo para la expedición de un código de recursos naturales, el cual se concretó con el Decreto 2811 de 1974 que armonizó la legislación dispersa existente en el momento y colocó la gestión ambiental en cabeza del ejecutivo. Esta norma creo el Código Nacional de los Recursos Renovables y de la Protección al Medio Ambiente, 
el cual se constituyó como uno de los primeros esfuerzos de integración sobre legislación ambiental en América Latina, constituyendo la principal norma sustantiva en materia ambiental en el País.

En este estatuto se establece que el ambiente es patrimonio común y que el manejo de los recursos naturales será de utilidad pública e interés social. También regula el manejo y aprovechamiento de los recursos naturales renovables, recursos del paisaje, la defensa del medio ambiente y recursos naturales renovables, contra la acción perjudicial antrópica y fenómenos naturales, los demás elementos y factores que conforman el ambiente o influyen en él, conocidos como elementos ambientales.

Finalmente este código ha sido reglamentado por los decretos 877 de 1976, en lo atinente a los recursos forestales, el decreto 1337 de 1978, en cuanto a educación ambiental, el decreto 1415 de 1978, que creó la comisión conjunta de asuntos ambientales, el decreto 1541 de 1978, que reglamentó las aguas no marítimas, el decreto 1608 de 1978, sobre fauna silvestre, el decreto 1741 de 1978, que reglamentó las áreas de recursos hidrobiológico, el decreto 1715 de 1978 que protege el paisaje, el decreto 2115 de 1978 permisos de aprovechamiento forestal, el decreto 2104 de 1983 residuos sólidos y el decreto 1594 de 1984, en lo referente al uso del agua y el vertimiento de residuos líquidos. Es importante destacar la ley 9 de 1979 (Código sanitario) que tiene como objeto preservar, y restaurar, las condiciones sanitarias relacionadas con la salud humana, el cual ha sido reglamentado por el decreto 1594 de 1984, mencionado anteriormente.

Con la promulgación de la Constitución de 1991, se estableció la función ecológica de la propiedad, señaló los deberes ambientales del Estado, los derechos ambientales de los ciudadanos, ordenó la formulación de políticas ambientales como parte del Plan Nacional de Desarrollo e introdujo la noción de desarrollo sostenible como meta para la sociedad. En 1993 fue expedida la Ley 99 del mismo año, en la que se estableció el Sistema Nacional Ambiental -SINA y se creó el Ministerio del Medio Ambiente como máxima autoridad en materia ambiental.

\section{Bibliografía}

Alvarenga y Lago. Estudio de caso: Gestión Ambiental en América Latina y el Caribe, el caso de Brasil. Banco Interamericano de Desarrollo, División del Medio Ambiente, Washington, D.C. 2000. En prensa.

Castro G. Los Trabajos de Ajuste y Combate: Naturaleza y Sociedad en la Historia de América Latina. Havana: Casa de las Américas. 1994.

De Alba E. Estudio de caso: Gestión Ambiental en América Latina y el Caribe, el caso de México. División del Medio Ambiente del BID. Washington, D.C BID. 2000. En prensa. 
Di Porto A. La tutela della "salubritas" fra editto e giurisprudenza, I: II ruolo di Labeone. Milano, Giuffrè, 1990.

Echarri L. Relación hombre - ambiente. Universidad de Navarra. 2007.

Espino JA. Estudio de caso: Gestión Ambiental en América Latina y el Caribe, el caso de Panamá. Washington, D.C: BID, División de Medio Ambiente. 2000. En prensa.

Espinoza G. Estudio de caso: Gestión Ambiental en América Latina y el Caribe, el caso de Chile. Washington, D.C: BID, División de Medio Ambiente. 2000. En prensa.

Fedeli P. La natura violata. Ecologia e mondo romano (Palermo, Sellerio, 1990).

Garcia MJ. Diccionario de jurisprudencia romana. 3aㅗ edición. Madrid, Dykinson, 1988; 4 reimpresión, Madrid, Dykinson, 2006), p. 168.

Hays SP. Explorations in Environmental History . Pittsburgh: Pittsburgh University Press. 1998.

Jaquenod SS. El Derecho ambiental y sus principios rectores (Madrid, Universidad Complutense, 1989)

Jordano J. La protección del derecho a un medio ambiente adecuado (Barcelona, Bosch, 1995).

Lara F. Editor. Código de Hammurabi, §§ 245 y 246 (Madrid, 1982), pp. 118 y 252, nota 592]

Llodrà Grimalt, Francesca, Lecciones de Derecho ambiental civil (Palma, Universitat de les Illes Balears, 2008).

Oroz J, Marcos MA. San Isidoro, Etymologiarum, XV, 11, $12^{\text {a }}$ edición, Madrid, Biblioteca de autores cristianos, 1994, II, pp. 250-251.

Romanorum Vita. Morir en época romana, 2013. http://www.romanorumvita.com/?p=6939 Acceso: noviembre 2 de 2015. 07:47 horas.

Rascón C, García J. Ley de las XII Tablas (Madrid, Tecnos. 1993).

Sánchez Pérez G. Desarrollo y medio ambiente, una mirada a Colombia. Fundación Universidad Autónoma de Colombia 2002; 1(1):79-88.

Zambrana P. La protección de las aguas frente a la contaminación y otros aspectos medioambientales en el Derecho romano y en el Derecho castellano medieval. Revista de Derecho. Pontificia Universidad Católica de Valparaíso. Valparaíso, Chile, $2 \stackrel{\circ}{ }$ Semestre de 2011: pp. $597-650$.

Zamora J. Precedentes romanos sobre el Derecho ambiental. La contaminación de las aguas, canalización de las aguas fecales y la tala ilícita forestal (Madrid, Edisofer, 2003).

José Eduardo Mohedano Córdoba. Energía e Historia: pocos recursos y muchos residuos. Copyright 2002-2004

(acceso: 16/11/2015) http://www.redcientifica.com/doc/doc200210070306.html 